\title{
SOME ASPECTS OF TRADITIONAL BELIEFS AS THEY AFFECT TUBERCULOSIS TREATMENT
}

\author{
C. MTHEMBU \\ RN, RM, DCCAI.
}

The Black man understands illness, physicial ailments and unhappiness as caused by unnatural factors such as:

- infliction or bestowal of illness and physical ailments by ancestors to punish the living for their sins of omission and commission as when rites are no longer performed or feasts are not celebrated;

- poisoning of food or drink by jealous wives, envious neighbours or relatives who have been offended;

- bewitchment through the agency of the wizards and witches.

The germ theory is not understood by the Black man to recognise a visit by plain it to the illiterate because of the minute structure of the germ and the fact that there is no term for germ in his language.

The signs of ill-health are enough for the Black man to recognise a visit by ancestors, poisoning or bewitchment. He then confirms his diagnosis of the cause of ill-health by going to the diviner who will tell him who caused the illness and how the illness had been caused, for example idliso (food poisoning), umego (jump over bewitchment) and ilumbo (illness of young lovers.)

The diviner tells the ill person what he is suffering from - he does not ask questions or do tedious tests.

The diviner either prescribes the treatment for the disease or refers the person to the herbalist, who usually prescribes. The prescription is to treat the cause. If displeasure of ancestors caused the illness, treatment would be to perform rites or to feast. The treatment for poisoning would involve neutralising the poison with emetics, enemas and so on.

The treatment is expected to be of short duration because the effect of the drugs is guaranteed.

If the condition does not improve or becomes worse another diviner is consulted. The patient pays for diagnosis and treatment by the diviner. Once treatment has been prescribed the client is not referred to another diviner even when treatment fails to improve the patient's condition. It is the patient who decides to visit another healer if he is dissatisfied.

The Black man prevents ill-health by fortification of his body and home.

Tuberculosis is an infectious disease caused by a mycobacterium bacillus unknown to the Black man. He needs health education about the causative agent so that he can associate the signs and symptoms he knows and experiences with the real cause.

The diagnosis by the diviner (isangoma) entails telling the patient what he is suffering from, whereas the medical practitioner asks the ill person what is wrong with him and when and how the illness started. The patient must be educated regarding the reason why the doctor has to ask questions and why sputum tests, $\mathrm{X}$-rays and heaf tests have to be done before the diagnosis can be confirmed.

Treatment for tuberculosis is prolonged whereas a Black person expects it to be of a short duration. The necessity for the lengthy treatment must be explained and the patient motivated for the long stay in hospital.

A person to be admitted into hospital fears death in hospital and ill-treatment by hospital personnel. He is distressed by his inability to continue his function in the community. Education about the need for hospitalisation is necessary to ensure early treatment and discharge.

Tuberculosis is not only treated with pills and injections but also by education about nutrition and general hygiene.

The prevention of tuberculosis should start at birth with the administration of Bacillus Calmette Guerin vaccine and parent education. A child is to be immunised at birth, at three months, on starting school and when leaving school. The predisposing causes of tuberculosis are to be eliminated through adequate nutrition, good housing, which includes sufficient ventilation, and treatment of debilitating conditions such as diabetus mellitus. 